\title{
A INFLUÊNCIA DO EXERCÍCIO FÍSICO SOBRE A ARTRITE REUMATOIDE - UMA REVISÃO DE LITERATURA
}

\author{
Jacqueline Moreira Lukachewski, Universidade Estadual de Maringá - UEM, Maringá, \\ Paraná - Brasil \\ Bianca Reis Cornelian, Universidade Estadual de Maringá - UEM, Maringá, Paraná - \\ Brasil \\ Carmem Patrícia Barbosa, Universidade Estadual de Maringá - UEM, Maringá, Paraná - \\ Brasil
}

\section{RESUMO}

A artrite reumatoide é uma doença inflamatória sistêmica, crônica, de caráter autoimune, caracterizada pelo acometimento das articulações com padrão simétrico. Está relacionada à inflamação da membrana sinovial que envolve as articulações sendo o processo inflamatório influenciado pelo aumento de citocinas pró-inflamatórias. O exercício físico reduz os riscos de diversas doenças e melhora a sintomatologia de várias outras, o objetivo desta pesquisa foi investigar os efeitos do exercício físico sobre a resposta inflamatória crônica provocada pela atrite reumatoide. Para tanto, foi realizada uma revisão bibliográfica compreendendo os anos 2000 a 2014 a qual foi realizada a partir de bases de dados como Pubmed e Scielo. Os descritores utilizados foram artrite reumatóide, exercício físico e natação. Artigos em animais e humanos portadores da AR foram selecionados. Evidenciou-se que o exercício físico tem um papel importante em relação à diminuição de citocinas pró-inflamatórias e por isso está associado à melhora na realização de atividades de vida diária de seus praticantes. Assim, este trabalho pode representar uma importante contribuição aos que pesquisam sobre a influência da prática do exercício físico sobre a artrite reumatoide favorecendo sua utilização como uma forma alternativa de terapia para o tratamento e/ou estabilização dessa doença.

Palavras-Chave: Artrite reumatóide; Exercício físico; Natação.

\section{THE INFLUENCE OF PHYSICAL EXERCISE ON ARTHRITIS RHEUMATOID - A LITERATURE REVIEW}

\begin{abstract}
Rheumatoid arthritis is a systemic inflammatory disease, chronic, autoimmune character, characterized by the involvement of the joints with symmetrical pattern. It is related to inflammation of the synovial membrane surrounding the joint inflammation being influenced by the increase of pro-inflammatory cytokines. Exercise reduces the risk of various diseases and improves symptoms in many others, the objective of this research was to investigate the effects of physical exercise on chronic inflammatory response caused by rheumatoid arthritis. To this end, a literature review comprising the years 2000 to 2014 which was held from databases such as Pubmed and Scielo was held. The descriptors used were rheumatoid arthritis, exercise and swimming. Articles in animals and human patients
\end{abstract}


with RA were selected. It became clear that exercise plays an important role in relation to the reduction of proinflammatory cytokines and therefore is associated with improvement in the performance of daily activities of its practitioners. This work may represent an important contribution to that research on the influence of physical exercise on rheumatoid arthritis favoring its use as an alternative form of therapy for the treatment and/or stabilization of the disease.

Key-Words: Rheumatoid arthritis; Exercise; Swimming.

\section{LA INFLUENCIA DE EJERCICIO FÍSICO EN LA ARTRITIS REUMATOIDE - UNA REVISIÓN DE LA LITERATURA}

\section{RESUMEN}

La artritis reumatoide es una enfermedad inflamatoria sistémica, carácter crónico, autoinmune, caracterizada por la implicación de las articulaciones con patrón simétrico. Está relacionado con la inflamación de la membrana sinovial que rodea a la inflamación de las articulaciones ser influenciado por el aumento de citoquinas pro-inflamatorias. El ejercicio reduce el riesgo de varias enfermedades y mejora los síntomas en muchos otros, el objetivo de esta investigación fue investigar los efectos del ejercicio físico sobre la respuesta inflamatoria crónica causada por la artritis reumatoide. Con este fin, una revisión bibliográfica que comprende los años 2000 a 2014 que se celebró del bases de datos como PubMed y Scielo se celebró. Los descriptores utilizados fueron la artritis reumatoide, el ejercicio y la natación. Se seleccionaron los artículos en animales y pacientes humanos con RA. Se hizo evidente que el ejercicio juega un papel importante en relación con la reducción de las citoquinas proinflamatorias y por lo tanto se asocia con una mejoría en el desempeño de las actividades diarias de sus practicantes. Este trabajo puede representar una importante contribución a que la investigación sobre la influencia del ejercicio físico en la artritis reumatoide favoreciendo su uso como una forma alternativa de terapia para el tratamiento y / o estabilización de la enfermedad.

Palabras-Clave: Artritis reumatóide; Ejercicio; Natación. 


\section{INTRODUÇÃO}

A artrite reumatoide (AR) é uma doença inflamatória crônica, de natureza autoimune e de etiologia e patogênese desconhecidas que afeta o sistema musculoesquelético. ${ }^{1-}$ ${ }^{3}$ Geralmente está associada a um alto grau de incapacidade física, morbidade e mortalidade, atingindo aproximadamente $1 \%$ da população mundial. ${ }^{4}$

É caracterizada por uma inflamação poliarticular simétrica que é frequentemente acompanhada por destruição articular e óssea que causa dor nas articulações sinoviais. Além disso, uma de suas principais características é a membrana sinovial modificada a qual se torna rica em fatores pró-inflamatórios. ${ }^{5-6}$

Tais alterações fazem com que o quadro clínico da doença, o qual inclui uma dor articular característica, seja agravado pela manhã causando rigidez matinal e fazendo com que o indivíduo não consiga realizar movimentos por, em média, até uma hora após o despertar. Além disso, é comum edema de tecidos moles e de articulações delicadas como as interfalângicas e, em alguns casos, podem aparecer nódulos reumatoides. ${ }^{7}$

O tratamento farmacológico da AR envolve usualmente a utilização de drogas antiinflamatórias esteroidais, não esteroidais e drogas antirreumáticas modificadoras da doença, as quais podem ser sintéticas ou naturais..$^{8-9}$ Entretanto, este arsenal terapêutico muitas vezes não modifica satisfatoriamente o processo patológico responsável pela inflamação crônica que acompanha esta doença, embora existam vários estudos demonstrando os benefícios que promovem na redução de seus sintomas clínicos. Assim, nem todas as alterações associadas à doença são corrigidas pelos diferentes fármacos, incluindo a perda da massa corporal, podendo também causar efeitos colaterais indesejáveis. ${ }^{10}$ Desta forma, embora existam vários tipos de tratamento para esta doença, a cura ainda não foi estabelecida.

O que tem sido empregado atualmente são tratamentos que objetivam a diminuição da dor e a melhora da mobilidade articular a fim de evitar a perda de função com consequente melhora na qualidade de vida dos portadores de AR. Neste contexto, o exercício físico é indicado, pois pode auxiliar a retardar a incapacidade funcional atuando como um 
coadjuvante capaz de melhorar a função articular. Segundo Alves e Bassitt, ${ }^{11}$ sua prática pode otimizar a lubrificação articular, manter bom nível de força muscular, diminuir a dor, melhorar a amplitude de movimento articular e diminuir a resistência articular.

No entanto, na tentativa de alcançar o alívio para a dor causada por esta doença articular, muitas vezes os portadores de AR optam por assumir a inatividade física a maior parte do tempo. Tal fato é extremamente prejudicial quando mantido além da fase aguda da doença uma vez que pode predispor a mais lesões articulares devido à diminuição na produção do líquido sinovial associada à imobilização prolongada. ${ }^{12}$

Por outro lado, as atividades aquáticas têm sido apontadas como um fator importante para o ganho de estabilidade articular uma vez que sua prática favorece o ganho gradativo de amplitude de movimento articular e força muscular. Além disso, tais atividades diminuem a sobrecarga articular devido ao fato da água proporcionar pouca compressão nas articulações - fenômeno associado à consequente redução da dor, melhora do tônus muscular e do sistema cardiovascular. ${ }^{13-14}$

\section{METODOLOGIA}

Esta pesquisa, do tipo bibliográfica, teve por objetivo investigar os efeitos do exercício físico sobre a resposta inflamatória crônica provocada pela atrite reumatoide, salientando a prática da natação e elencando os reais benefícios que tal prática pode gerar ao portador da doença que a pratica, principalmente em relação à analgesia. Para tanto, foram selecionados 75 artigos, dos quais 43 foram utilizados neste estudo. A seleção baseou-se nos seguintes critérios de inclusão: os textos deveriam abordar exclusivamente a artrite reumatoide como problemática e a relação do exercício físico com a artrite (benefícios, malefícios e influência sobre o sistema imunológico, etc.). O único critério de exclusão foi a não abordagem dos temas acima. Assim, os descritores artrite reumatoide, exercício físico e natação foram usados. Artigos em humanos e em animais foram selecionados sem preferência específica, sendo a única exigência em relação à seleção, o fato de evidenciarem o efeito anti-inflamatório do exercício físico sobre a doença bem como sua influência na percepção da dor.

Conexões: revista da Faculdade de Educação Física da UNICAMP, Campinas, v. 13, n. 4, p. 119-136, out./dez. 2015. ISSN: 1983-9030. 


\section{REVISÃO DE LITERATURA}

\section{ARTRITE REUMATOIDE}

A artrite reumatoide (AR) é considerada uma doença autoimune de origem desconhecida, caracterizada pela deformidade e destruição nas múltiplas articulações. Pode se manifestar de várias formas, mas inicialmente acomete as articulações de maneira simétrica vindo posteriormente a avançar para outras estruturas anatômicas como coração, pulmão, rim e pele. Sua prevalência é maior em mulheres sendo que, no total, 1\% da população mundial é acometida atualmente por essa doença. ${ }^{4}$ Seu início pode se dar em todas as faixas etárias, entretanto é mais comum entre 45 e 65 anos. Devido sua incapacitação progressiva, tarefas diárias consideradas simples, como levantar-se da cama ou vestir-se, podem se tornar difíceis acarretando dependência funcional de seus portadores e, consequentemente, maiores gastos tanto para o próprio indivíduo acometido pela doença quanto para a sociedade. ${ }^{15}$

A AR está relacionada à inflamação da membrana sinovial a qual envolve as principais articulações do corpo, cuja função é produzir o líquido sinovial a fim de nutrir e lubrificar a cartilagem articular permitindo o movimento normal. Quando esta membrana inflama, torna-se mais espessa acarretando aumento de volume e comprometendo a produção do líquido sinovial. É comum o líquido apresentar características inflamatórias (tais como maior quantidade de células imunes) causando destruição progressivamente das cartilagens que revestem as articulações, prejudicando a função articular, limitando os movimentos e causando dor. ${ }^{16}$

O tratamento da AR deve ser iniciado o mais rapidamente possível sendo diferenciado e específico a cada portador considerando idade, gravidade da doença e tratamentos pregressos como fatores norteadores. É relevante ressaltar que, embora a cura ainda não seja plenamente possível, com o tratamento adequado seus sinais e sintomas podem ser minimizados e, inclusive, o processo inflamatório pode ser diminuído. ${ }^{16}$

Esse processo inflamatório ocorre inicialmente na membrana sinovial (sinovite) cuja função é produzir o líquido sinovial e nutrir a região articular, além de permitir o movimento normal das articulações. No entanto, em resposta à inflamação, ocorre Conexões: revista da Faculdade de Educação Física da UNICAMP, Campinas, v. 13, n. 4, p. 119-136, out./dez. 2015. ISSN: 1983-9030. 
hiperplasia da membrana sinovial (processo conhecido como pannus) a fim de recompor o líquido sinovial. Todavia, há simultânea ativação de células endoteliais culminando em aumento na produção de citocinas pró-inflamatórias o que potencializa os danos articulares e a progressão da doença. ${ }^{17-18}$

Citocinas pró-inflamatórias como o fator de necrose tumoral (TNF- $\alpha$ ) e as interleucinas (IL-1 $\beta$, IL6 e IL-17), contribuem para a destruição da cartilagem articular. O processo inflamatório aumenta principalmente a quantidade de IL-17 no tecido inflamado a qual estimula a produção e/ou liberação das demais citocinas pró-inflamatórias, com destaque para o TNF- $\alpha$. Este, por sua vez, estimula as células sinoviais a produzirem enzimas hidrolíticas capazes de destruir progressivamente a articulação. ${ }^{19}$ Antagonicamente, citocinas anti-inflamatórias evidenciadas como protetoras articulares (como é o caso das interleucinas IL-4, IL-10 e IL-13) estão presentes em menor quantidade no líquido sinovial de portadores de AR. ${ }^{20}$

Assim, além da inflamação sinovial, também é característica da artrite reumatoide humana e da artrite experimental desenvolvida em modelos animais, a erosão cartilagínea e óssea, a artralgia e a incapacidade física. Em ratos, por exemplo, a artrite induzida por adjuvante pode ocasionar muitos sinais e sintomas semelhantes àqueles observados em portadores da AR humana. ${ }^{21}$

Por isso, estudos em animais são realizados com o objetivo de verificar a melhor forma de tratar a doença e ter melhor compreensão de condições clínicas como dor e edema articular. A artrite induzida por adjuvante (AIA), por exemplo, é um modelo experimental de doença autoimune amplamente usado devido tais semelhanças. Neste modelo, a artrite é ocasionada pela injeção do adjuvante completo de Freund (ACF) o qual é composto por óleo de parafina contendo mono-oleato de manitol como surfactante em suspensão com uma microbactéria morta O desenvolvimento da AIA se dá pela injeção intraplantar do ACF a qual pode ser feita, mais comumente, na pata posterior ou na cauda do animal. ${ }^{22}$

A administração do ACF causa dor inflamatória severa localizada ao redor da área injetada e aumento da circunferência da pata (edema) sendo por isso capaz de induzir uma resposta inflamatória prolongada que pode ser avaliada no decorrer de seu desenvolvimento. ${ }^{23}$ Além

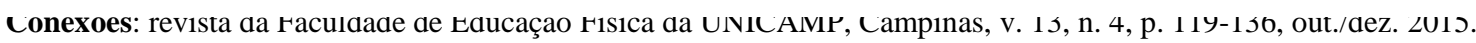
ISSN: 1983-9030. 
disso, o desenvolvimento da reação inflamatória produz hiperemia como sinal característico e manifestações imunológicas. ${ }^{24}$ Tais sinais e sintomas são, ao menos em parte, atribuídos às citocinas pró-inflamatórias IL-1 $\beta$ e TNF- $\alpha$ as quais estão presentes em níveis elevados nas articulações artríticas tanto em animais quanto em humanos. ${ }^{25-26}$

Considerando as limitações funcionais decorrentes da AR o diagnóstico precoce e o início imediato do tratamento são fundamentais para o controle da doença. Isto porque o acometimento progressivo da membrana sinovial pode aumentar a destruição osteoarticular determinando a invasão da cartilagem e a erosão do osso subcondral por um processo destrutivo local conhecido como pannus reumatoide. ${ }^{25,27}$

Todos estes eventos estão associados à intensa dor que o indivíduo com AR apresenta com o evoluir da doença sem tratamento. De igual modo, as modificações desencadeadas pelo processo inflamatório desencadeiam edema articular de caráter simétrico, rigidez matinal prolongada a qual, em caso de inflamação mais severa, pode chegar a até uma hora de rigidez após o despertar. A evolução progressiva da doença foi relatada por Mota et al. ${ }^{28}$ os quais salientaram que na fase inicial da doença a intervenção terapêutica é mais eficaz. Para estes autores, essa fase envolve os 12 primeiros meses de sinais e sintomas embora seja difícil a identificação precoce da AR visto que alterações sorológicas e radiográficas muitas vezes são ausentes no início da doença. Nesta fase, o indivíduo apresenta acometimento simétrico de pequenas articulações como punhos, mãos e pés em contrapartida aos estágios tardios onde os ombros, cotovelos, quadris, joelhos e tornozelos são acometidos pela inflamação. Os referidos autores também salientam que as manifestações da AR podem ser extra articulares uma vez que se trata de uma doença sistêmica. Assim, febre, fadiga, mialgia, derrame articular, calor local e, em estágio grave, quadros cutâneos, pleuropulmonares e cardíacos são comuns.

Em decorrência deste quadro clínico tão comprometedor, muitas vezes indivíduos com AR tornam-se inativos fisicamente, o que pode diminuir a capacidade funcional e a qualidade de vida dos mesmos além de acarretar graves problemas de saúde. ${ }^{29}$ Por isso, embora profissionais da saúde sugiram repouso aos pacientes com AR durante as crises comuns à fase aguda, a melhora do processo inflamatório deve ser acompanhada de exercício físico 
supervisionado a fim de manter a estabilidade articular, o trofismo muscular, a força e a resistência muscular e minimizar o surgimento de fadiga. ${ }^{30}$

\section{EXERCÍCIO FÍSICO}

Os objetivos dos diferentes tratamentos da AR incluem a prevenção e o controle da lesão articular e, consequentemente, a prevenção da perda dos movimentos, a analgesia e a melhora de aspectos da qualidade de vida dos indivíduos artríticos. Para tanto, algumas condutas são essenciais durante as várias fases de desenvolvimento da doença. O repouso, por exemplo, é essencial à diminuição da dor e da inflamação na fase aguda, porém se mantido de maneira prolongada, pode causar enrijecimento de algumas estruturas anatômicas da articulação sinovial comprometendo a realização dos movimentos. Por isso, o acompanhamento desses indivíduos deve ocorrer desde o início da doença com orientação e programas terapêuticos específicos voltados à proteção articular, ao ganho de mobilidade e à manutenção da funcionalidade do sistema cardiorrespiratório. ${ }^{31}$

Diante disso, numa fase tardia da doença, o profissional de educação física, junto a uma equipe multiprofissional, pode contribuir para que pessoas artríticas continuem a exercer suas atividades de vida diária por meio da realização de exercícios físicos que garantam o fortalecimento e a flexibilidade da musculatura, bem como a proteção articular e periarticular. Conforme relata Costa e Beck, ${ }^{16}$ o programa deve ser abrangente envolvendo também exercícios de flexibilidade e deve priorizar a realização do movimento com cargas moderadas. Tais autores, após uma extensa pesquisa bibliográfica sobre o tema, concluíram que exercícios resistidos, alongamentos e relaxamento devem ser estimulados embora a terapêutica deva contemplar períodos alternados de atividades e repouso. Assim, para eles:

Atividade aeróbica, exercícios resistidos, alongamentos e relaxamentos devem ser estimulados observando-se os critérios de tolerância ao exercício e à fadiga. Repouso e exercício devem ser enfatizados reconhecendo-se que a degeneração articular na AR é maior quando o repouso é prolongado. ${ }^{16: 69}$

Desta forma, o exercício físico é apontado como capaz de trazer benefícios ao portador de AR, seja diminuindo a dor ou retardando a incapacidade funcional por meio da manutenção da função articular. Este fato foi identificado por Gomes ${ }^{22}$ em um estudo que avaliou o efeito do exercício físico sobre a nocicepção, edema articular e migração celular 
em ratas com artrite induzida por adjuvante completo de Freund (ACF). Foram realizados exercícios de deambulação progressiva acrescentando 1 minuto/dia até perfazer dez minutos no décimo dia de experimento. Os exercícios foram realizados em um cilindro de aço inox, com velocidade contínua de $3 \mathrm{rpm}$. Os resultados mostraram que o exercício progressivo causou efeito positivo na diminuição da dor, do edema e da migração de leucócitos no fluído sinovial na articulação tíbio-femoral. Para o autor, é possível que haja correlação entre uma provável liberação endógena de corticoide durante o exercício sendo esta capaz de minimizar a nocicepção, o edema e a migração de leucócitos na articulação.

Em concordância com os efeitos benéficos apontados por Gomes, ${ }^{22}$ o exercício modula a atuação das células do sistema imunológico de forma dependente do planejamento do exercício. Assim, quando o volume e a intensidade do treinamento forem estabelecidos corretamente e o exercício considerado moderado, há aumento dos mecanismos de defesas. Por outro lado, exercícios intensos e prolongados estão associados à diminuição das respostas imunológicas e alterações na atuação de neutrófilos, macrófagos e linfócitos. ${ }^{20}$

Um estudo realizado por Petersen e Pedersen ${ }^{32}$ investigou o efeito anti-inflamatório do exercício. Estes autores constataram que a prática regular do exercício minimizou o aumento das citocinas pró-inflamatórias TNF- $\alpha$ e IL-1 $\beta$, mas predispôs o aumento da IL-6. Esta citocina foi apontada pelos autores como sendo a primeira a aparecer na corrente sanguínea durante o exercício, embora tenha diminuído no pós-exercício em resposta ao treinamento. Para eles, a atuação da IL-6 independe do TNF- $\alpha$ e sua diminuição no pósexercício decorre do fato do exercício liberar citocinas anti-inflamatórias na corrente sanguínea.

Complementarmente, o estudo de Krinski et al. ${ }^{33}$ salientou que o aumento da IL-6 durante a prática do exercício físico pode estar relacionado às contrações musculares que culminam em pequenas rupturas das miofibrilas predispondo à elevação dos níveis séricos de citocinas pró-inflamatórias. Além disso, também existe uma correlação entre o aumento da IL-6 e o tipo de exercício praticado, o período de sua duração, sua intensidade, a massa muscular que o indivíduo apresenta pregressamente e sua capacidade de resistência física. $^{32}$ 
Vale ressaltar que a IL-6, por si só, não induz à inflamação e mesmo sendo reconhecidamente caracterizada como uma citocina pró-inflamatória e prejudicial principalmente na $\mathrm{AR}$, à medida que o exercício a libera, há concomitante aumento nos níveis circulantes de citocinas anti-inflamatórias como a IL-10. Além disso, o nível de IL-6 diminui durante o período de descanso, mas mantém-se significantemente aumentado (em média por até quatro horas) durante o período de repouso após um exercício intenso como a maratona. ${ }^{34-35}$

Considerando que exercícios de alta intensidade podem elevar algumas citocinas próinflamatórias enquanto treinamentos de intensidade moderada podem baixá-las, o tipo de exercício físico, a intensidade e a duração devem ser bem planejados quando se trata de pacientes com AR. Desta forma, o exercício físico é considerado benéfico para pacientes com AR, quando bem elaborado e supervisionado. Seu intento principal é melhorar a aptidão cardiorrespiratória e cardiovascular (diminuídas em portadores de AR devido à inatividade física), a massa e a força muscular, e o desempenho físico sem piorar a lesão articular característica da doença. Todavia, é evidente que a prática do exercício físico deve ser realizada com cautela, sendo analisada intensidade, frequência e volume a fim de se obter resultados satisfatórios e não comprometer a saúde do indivíduo. ${ }^{36-37}$ Além disso, para Dario et al., ${ }^{38}$ deve-se estabelecer um protocolo quanto à duração e à intensidade bem como deve-se considerar o estado geral do doente e o fato de que a doença ocorre de forma cíclica analisando a fase da mesma.

Assim, os exercícios devem ser trabalhados associando treinamento resistido e treinamento aeróbio. Caminhar, pedalar, correr, dançar e fazer hidroginástica são exercícios aeróbios indicados. Além disso, exercícios na água podem ser eficazes devido à diminuição que causam na sensibilidade articular, à melhora na amplitude articular e no bem estar psicológico. ${ }^{39-40}$

Um estudo realizado por Prestes et al. ${ }^{35}$ verificou os efeitos de cinco sessões consecutivas de natação em ratos machos da linhagem Wistar. Os autores realizaram um aumento progressivo na carga fazendo com que a intensidade aumentasse de leve à moderada. Para tanto, cargas adicionais de 5\% do peso corporal dos animais foram gradativamente adicionadas às suas regiões dorsais, mas permaneceram numa intensidade abaixo do limiar Conexões: revista da Faculdade de Educação Física da UNICAMP, Campinas, v. 13, n. 4, p. 119-136, out./dez. 2015. ISSN: 1983-9030. 
anaeróbio. Foi analisada a influência do exercício físico sobre o número de leucócitos totais, de linfócitos e a concentração de citocinas circulantes. Estes pesquisadores concluíram que animais praticantes de exercício físico tiveram redução significativa na concentração sérica de TNF- $\alpha$. Tal fato é relevante uma vez que esta citocina é considerada um fator pró-inflamatório característico da AR sendo apontada como a responsável por manter o processo inflamatório ativo desta doença. ${ }^{5}$

Outro estudo realizado por Prestes et al. ${ }^{41}$ avaliou ratos Wistar, machos, com dois meses de idade. Estes animais foram divididos em três grupos: grupo controle sedentário (C), grupo exercício físico agudo EXL (o qual realizou uma única sessão de exercício em intensidade leve até à exaustão) e grupo exercício físico agudo EXM (o qual realizou uma única sessão de exercício em intensidade moderada até exaustão). O exercício físico pesquisado neste estudo foi a natação a qual foi realizada em um tanque com temperatura de $32^{\circ} \mathrm{C}$, sendo a intensidade definida por cargas adicionadas na região dorsal do animal até um total de $5 \%$ do seu peso corporal no caso do exercício moderado. A exaustão foi considerada quando os animais afundavam no tanque e não voltavam à superfície. Quando os grupos EXL e EXM foram comparados em relação à liberação de IL-6, observou-se uma redução de 40,3\% na concentração de IL-6 no grupo EXM. Além disso, o grupo EXM apresentou uma redução de $26 \%$ na concentração de TNF- $\alpha$ quando comparado ao grupo controle confirmando que o exercício físico realizado na água em intensidade moderada contribui para a melhora do processo inflamatório.

Em outro estudo, foram selecionados 115 pacientes com AR e submetidos a uma sessão semanal de 30 minutos de hidroterapia ou exercícios em solo (caminhada) durante seis semanas. Ao comparar os efeitos de exercícios físicos realizados por pacientes com AR na água e no solo chegou-se à conclusão que imediatamente após o treinamento realizado na água os indivíduos pesquisados relataram melhora na percepção subjetiva da dor de forma mais expressiva do que aqueles que realizaram exercícios fora d’água. ${ }^{42}$

Um estudo realizou exercícios duas vezes na semana durante 12 semanas, com duração de 45 minutos para indivíduos com AR, sendo eles 20 indivíduos que praticaram os exercícios e 23 continuaram com suas atividades normais. Os exercícios aplicados foram de capacidade aeróbia de $70 \%$ da frequência cardíaca máxima, força muscular e resistência Conexões: revista da Faculdade de Educação Física da UNICAMP, Campinas, v. 13, n. 4, p. 119-136, out./dez. 2015. ISSN: 1983-9030. 
muscular nos membros superiores e inferiores, além de flexibilidade, coordenação e relaxamento. Neste estudo os indivíduos submetidos ao exercício melhoraram significativamente a resistência muscular, enquanto que a capacidade aeróbica não houve melhoras significativas. É importante ressaltar que em se tratando de exercícios realizados na água, a temperatura da água deve estar ajustada para que seja adequadamente morna para que, além de reduzir a sobrecarga sobre as articulações dolorosas, promova um relaxamento muscular. ${ }^{43}$ Assim, sua prática pode diminuir a dor e a pressão articular de pacientes com AR podendo ser um complemento no tratamento desta doença.

\section{CONSIDERAÇÕES FINAIS}

Na presente revisão observou-se que a artrite reumatoide é uma doença que afeta a economia uma vez que atinge cerca de $1 \%$ da população mundial e requer tratamento de alto custo. Além disso, o portador possui baixa qualidade de vida e torna-se sedentário em decorrência da própria evolução da doença.

Seu tratamento envolve, além de fármacos utilizados para o controle da inflamação, o exercício físico o qual pode contribuir satisfatoriamente para a melhora do quadro clínico bem como da qualidade de vida de seus portadores. Assim, o exercício físico pode ser considerado um complemento no tratamento da artrite reumatoide, embora sua realização culmine na liberação de citocinas pró-inflamatórias como a IL-6. No entanto, esta citocina pode ser considerada com caráter pró e anti-inflamatório, pois após sua liberação há também a liberação de IL-10 - uma citocina amplamente anti-inflamatória que minimiza a liberação de TNF- $\alpha$, além de baixar a concentração sérica de IL-6.

Assim, o treinamento físico é apontado como capaz de melhorar a funcionalidade de pacientes com AR, sendo a natação considerada um esporte de baixo impacto que muito colabora para a redução da dor articular e melhora dos movimentos. Sua prática é também importante para a redução de sérios problemas de saúde, como por exemplo, doenças cardiovasculares, diabetes e acidente vascular encefálico aumentando a sobrevida destas pessoas.

Conexões: revista da Faculdade de Educação Física da UNICAMP, Campinas, v. 13, n. 4, p. 119-136, out./dez. 2015. ISSN: 1983-9030. 
No entanto em relação à AR, não há ainda um consenso absoluto entre os pesquisadores no que refere à fase ideal de utilização do exercício físico, bem como intensidade e volume a serem adotados, uma vez que esta doença é caracterizada por períodos de crises e remissões os quais variam amplamente em os portadores. Assim, este estudo representa o início de uma possível contribuição à pesquisa sobre o tema, incentivando novos estudos que melhor elucidem o que de fato os exercícios físicos podem proporcionar quando iniciados desde o início da doença. Desta forma, novos estudos devem ser realizados em relação a como os diferentes programas de exercícios podem contribuir para a melhora da dor, do edema articular e do efeito anti-inflamatório de maneira dependente de intensidade e duração. Isso posto, este método poderá fazer parte do tratamento básico proposto para pessoas com artrite reumatoide.

\section{REFERÊNCIAS}

${ }^{1}$ FELSON, D. T. Comparing the prevalence of rheumatic diseases in China with the rest of the world. Arthritis Research \& Therapy, London, v. 10, n.1, p. 106, 2008.

${ }^{2}$ LESUIS, N. et al. Gender and the treatment of immune-mediated chronic inflammatory diseases: rheumatoid arthritis, inflammatory bowel disease and psoriasis: an observational study. BMC: medicine, v. 1, p. 10-82, aug. 2012.

${ }^{3}$ SILVA, S. S. S. L. et al. O impacto da atividade física na artrite reumatoide. Revista Pesquisa em Fisioterapia, Bahia, v. 3, n. 2, 118-130, dez. 2013.

${ }^{4}$ DAVIS, J. M.; MATTESON E. L. My treatment approach to rheumatoid arthriti. Mayo Clinic Proceedings, Rochester, v. 87, n. 7, p. 659-673, july 2012.

${ }^{5}$ NAGASHIMA, T. et al. Apoptosis of rheumatoid synovial cells by statins through the blocking of protein geranylgeranylation: a potential therapeutic approach to rheumatoid arthritis. Arthritis and Rheumatism, Hoboken, v. 54, n. 2, p. 579-86, feb. 2006. 
${ }^{6}$ BIANCHI, W. A. et al. Terapia biológica em artrite reumatoide novas perspectivas no controle e remissão. Jornal Brasileiro de Medicina, Rio de Janeiro, v. 100, n. 2, maio/jun. 2012.

${ }^{7}$ KÜLKAMP, W. et al. Artrite Reumatoide e exercício físico: resgate histórico e cenário atual. Revista Brasileira de Atividade Física e Saúde, Londrina, v. 14, n. 1, p. 55-64, jun. 2009.

${ }^{8}$ O'DELL, J. R. Therapeutic strategies for rheumatoid arthritis. New England Journal of Medicine, Boston, v. 350, n. 25, p. 2591-602, june 2004.

${ }^{9}$ BAGATINI, F. et al. Potenciais interações medicamentosas em pacientes com artrite reumatoide. Revista Brasileira de Reumatologia, São Paulo, v. 51, n. 1, jan./fev. 2011.

${ }^{10}$ BENDELE, A. M. et al. Combination benefit of treatment with the cytokine inhibitors interleukin-1 receptor antagonist and PEGylated soluble tumor necrosis factor receptor type I in animal models of rheumatoid arthritis. Arthritis and Pheumatism, Hoboken, v.43, n. 12, p. 2648-2659, dec. 2000.

${ }^{11}$ ALVES, J. C.; BASSITT, D. P. Quality of life and functional capacity of elderly women with knee osteoarthritis. Einstein (São Paulo), São Paulo, v. 11, n. 2, p. 209-215, apr./june 2013.

${ }^{12}$ BERTOLINI, S. M. M. G. et al. Resposta das estruturas articulares do joelho de ratos pós-imobilização. Revista Ciência e Saúde, Brasília, v. 2, n. 1, p. 8-15, jan./jun. 2009.

${ }^{13}$ CAMPOS, R. P. et al. Contribuição da natação para a reabilitação da bursite de ombro pós-fase aguda. Revista Brasileira de Ciência e Movimento, Brasília, v. 20, n. 2, p. 119126, abr./jun. 2012.

${ }^{14}$ SANTANA, V. S.; EUZÉBIO, C. J. V.; GALVÃO, V. L. Benefícios da fisioterapia aquática no paciente com artrite reumatoide: revisão de literatura. Revista Pesquisa em Fisioterapia, Bahia, v. 3, n. 1, p. 50-66, jul. 2013.

Conexões: revista da Faculdade de Educação Física da UNICAMP, Campinas, v. 13, n. 4, p. 119-136, out./dez. 2015. ISSN: 1983-9030. 
${ }^{15}$ MOTA, L. M. H.; LAURINDO, I. M. M.; SANTOS NETO, L. L. S. Características demográficas e clínicas de uma coorte de pacientes com artrite reumatoide inicial. Revista Brasileira de Reumatologia, São Paulo, v. 50, n. 3, p. 235-48, 2010.

${ }^{16}$ COSTA, J. P.; BECK, S. T. Avanços no diagnóstico e tratamento da artrite reumatoide. Saúde (Santa Maria), Santa Maria, v. 37, n. 1, p. 65-76, 2011.

${ }^{17}$ CICONELLI, R. M. Artrite reumatoide: tratamento. Revista Sinopse de Reumatologia, São Paulo, v. 3, n. 2, p. 1-17, jun. 2005.

${ }^{18}$ GIRIBELA, C. R. G. et al. Função e disfunção endotelial: da fisiopatologia às perspectivas de uso em pesquisa e na prática clínica. Revista Brasileira de Hipertensão, São Paulo, v. 18, n. 1, p. 27-32, 2011.

${ }^{19}$ SILVA, G. L da. Loci de Suscetibilidade genética à artrite reumatoide estabelecem redes de regulação transcriocional com outros genes. 2010. Dissertação (Mestrado) Faculdade de Medicina de Ribeirão Preto, Universidade de São Paulo, Ribeirão Preto, São Paulo, 2010.

${ }^{20}$ BELOTTO, M. F. Efeito do exercício físico sobre o estado inflamatório de diabéticos. EFDesportes.com: revista digital, Buenos Aires, v. 16, n. 159, ago. 2011. Disponível em: www.efdeportes.com/efd159/efeito-do-exercício-físico-sobre-diabéticos.htm.

${ }^{21}$ GOMES, R. P. et al. Efeitos de um minuto e dez minutos de deambulação em ratos com artrite induzida por adjuvante completo de Freund sobre os sintomas de dor e edema. Revista Brasileira de Reumatologia, São Paulo, v. 54, n. 2, p. 83-89, 2014.

${ }^{22}$ GOMES, R. P. Atividade física no tratamento de artrite induzida por adjuvante de Freund: efeitos na nocicepção, edema e migração celular. 2008. 107 f. Dissertação (Mestrado) - Universidade do Estado de Santa Catarina, Florianópolis, 2008.

${ }^{23}$ SANTOS, D. S. Avaliação do efeito anti-inflamatório do toque terapêutico no Conexões: revista da Faculdade de Educação Física da UNICAMP, Campinas, v. 13, n. 4, p. 119-136, out./dez. 2015. ISSN: 1983-9030. 
modelo experimental de edema de pata induzido por adjuvante completo de Freund em camundongo. 2001. 61 f. Doutorado (Tese) - Universidade de São Paulo, Ribeirão Preto, São Paulo, 2011.

${ }^{24} \mathrm{LI}, \mathrm{W}$. M. et al. Analgesic effect of electroacupuncture on complete freund's adjuvantinduced inflammatory pain in mice: a model of antipain treatment by acupuncture in mice. Japanese Journal of Physiology, Tokio, v. 55, no. 6, p. 339-344, 2005.

${ }^{25}$ FALEIRO, L. R.; ARAÚJO, L. H. R.; VARAVALLO, M. A. A terapia anti-TNF- $\alpha$ na artrite reumatoide. Semina: ciências biológicas e da saúde, Londrina, v. 32, n. 1, p. 77-94, jan./jun. 2011.

${ }^{26}$ MERINI, L. R. et al. Citocinas pró-inflamatórias em artrite induzida por adjuvante: uma revisão da ação imunomoduladora de substâncias bioativas. Scientia Amazonia, Manaus, v.1, n. 3, p. 27-39, 2012. Disponível em:

www.scientia.ufam.edu.br/attachments/article/16/v.\%201\%20n.3\%2027-39.\%202012.pdf.

${ }^{27}$ BRENOL, C. V. et al. Artrite reumatoide e aterosclerose. Revista da Associação Médica Brasileira, São Paulo, v. 53, n. 5, p. 465-470, 2007.

${ }^{28}$ MOTA, L. M. H. et al. Consenso da Sociedade Brasileira de Reumatologia 2011 para diagnóstico e avaliação inicial da artrite reumatoide. Revista Brasileira de Reumatologia, São Paulo, v. 51, n. 3, p. 199-219, 2011.

${ }^{29}$ CORBACHO, M. I.; DAPUETO, J. J. Avaliação da capacidade funcional e da qualidade de vida de pacientes com artrite reumatoide. Revista Brasileira de Reumatologia, São Paulo, v. 50, n. 1, p. 32-43, 2010.

${ }^{30}$ BIANCHI, W. A. et al. Análise da associação da fadiga com variáveis clínicas e psicológicas em uma série de 371 pacientes brasileiros com artrite reumatoide. Revista Brasileira de Reumatologia, São Paulo, v. 54, n. 3, jun. 2014. 
${ }^{31}$ MOTA, L. M. H. et al. Consenso 2012 da Sociedade Brasileira de Reumatologia para o tratamento da artrite reumatoide. Revista Brasileira de Reumatologia, São Paulo, v. 52, n. 2, p. 135-174, mar./abr. 2012.

${ }^{32}$ PETERSEN, A. M. W.; PEDERSEN, B. K. The anti-inflammatory effect of exercise. Journal of Applied Physiology, Bethesda, v. 98, n. 4, p. 1154-1162, 2005.

${ }^{33}$ KRINSKI, K. et al. Efeitos do exercício físico no sistema imunológico. Revista Brasileira de Medicina, São Paulo, v. 67, n. 7, p. 228-233, 2010.

${ }^{34}$ PEDERSEN, B. K. et al. Role of myokines in exercise and metabolism. Journal of Applied Physiology, v. 103, p. 1093-1098, sept. 2007.

${ }^{35}$ PRESTES, J. et al. Influência do exercício físico em diferentes intensidades sobre o número de leucócitos, linfócitos e citocinas circulantes. Revista Brasileira de Medicina, São Paulo, v. 65, n. 3, p. 56-60, mar. 2008.

${ }^{36}$ COONEY, J. K. et al. Benefits of exercise in rheumatoid arthritis. Journal of Aging Research, New York, v. 2011, p. 1-14, feb. 2011.

${ }^{37}$ VIACAVA, P. R. et al. Efeito do exercício aeróbico em modelo experimental de artrite. Clinical and Biomedical Researd, Porto Alegre, v. 34, n. 1, p. 28-39, 2014.

${ }^{38}$ DARIO, A. B. et al. Alterações psicológicas e exercício físico em pacientes com artrite reumatoide. Motricidade, Santa Maria da Feira, v. 6, n. 3, p. 21-30, 2010.

${ }^{39}$ FERREIRA, L. R. F. et al. Efeitos da reabilitação aquática na sintomatologia e qualidade de vida de portadoras de artrite reumatoide. Fisioterapia e Pesquisa, v. 15, n. 2, São Paulo, p. 136-141, abr./jun. 2008.

${ }^{40}$ CALEGARI, R.; TOIGO, A. M. Benefícios da hidroginástica para indivíduos com artrite reumatóide. EFDeportes.com: revista digital, Buenos Aires, v. 19, n. 193, 2014. 
${ }^{41}$ PRESTES, J. et al. Influência do exercício físico agudo realizado até a exaustão sobre o número de leucócitos e citocinas circulantes. Fitness Performance Journal, Rio de Janeiro, v. 6, n. 1, p. 32-37, jan./fev. 2007.

${ }^{42}$ EVERSDEN, L.et al. A pragmatic randomised controlled trial of hydrotherapy and land exercises on overall well-being and quality of life in rheumatoid arthritis. BMC Musculoskeletal Disorders, Bethesda, v. 8, n. 23, mar. 2007.

${ }^{43}$ BILBERG, A.; AHLMÉN, M.; MANNERKORPI, K. Moderately intensive exercise in a temperate pool for patients with rheumatoid arthritis: a randomised controlled study. Rheumatology, Oxford, v. 44, n. 4, p. 502-8, 2005.

Recebido em: 12 maio 2015 Aceito em:16 out. 2015 Contato: jacquelinemoreira01@hotmail.com 